\title{
"The best or the worst" end up in product development partnerships
}

Published at www.cmaj.ca on Oct. 14

$\mathrm{W}$ ith aggregate funding of roughly US $\$ 3.5$ billion over the course of the last two decades, product development partnerships (PDPs) have become an industry unto themselves.

They aim to develop treatments for infectious and neglected diseases of the developing world, as well as diagnostics and preventive medicines such as vaccines or microbicides, and proponents argue that they are reconfiguring the global health landscape because they are delivering on their promise: at least 93 products to date.

Funding for PDPs continues to spiral, rising to roughly US\$580.1 million from US\$460.9 million in 2007 (and scant tens of millions of dollars that the first ones received when they were established in the mid-1900s), according to the G-Finder, a global database maintained by the London, Englandbased George Institute for International Health (https://studies.thegeorgeinstitute .org/gfinder_report/search.jsp).

They're the favoured form of investment by the Bill \& Melinda Gates Foundation, which has provided roughly twothirds of the US\$3.5 billion that the 26 global PDPs have received to date. Most of the remainder has come from other philanthropic foundations or bilateral and government aid agencies, including the United States Agency for International Development, the Department for International Development in the United Kingdom, along with \$120 million from the Canadian International Development Agency.

Proponents also hope that governments around the world can be placed under increased pressure to reverse their recent rollbacks on PDP investment and funnel more money in the future into such initiatives, which include the International AIDS Vaccine Initiative, the Drugs for Neglected

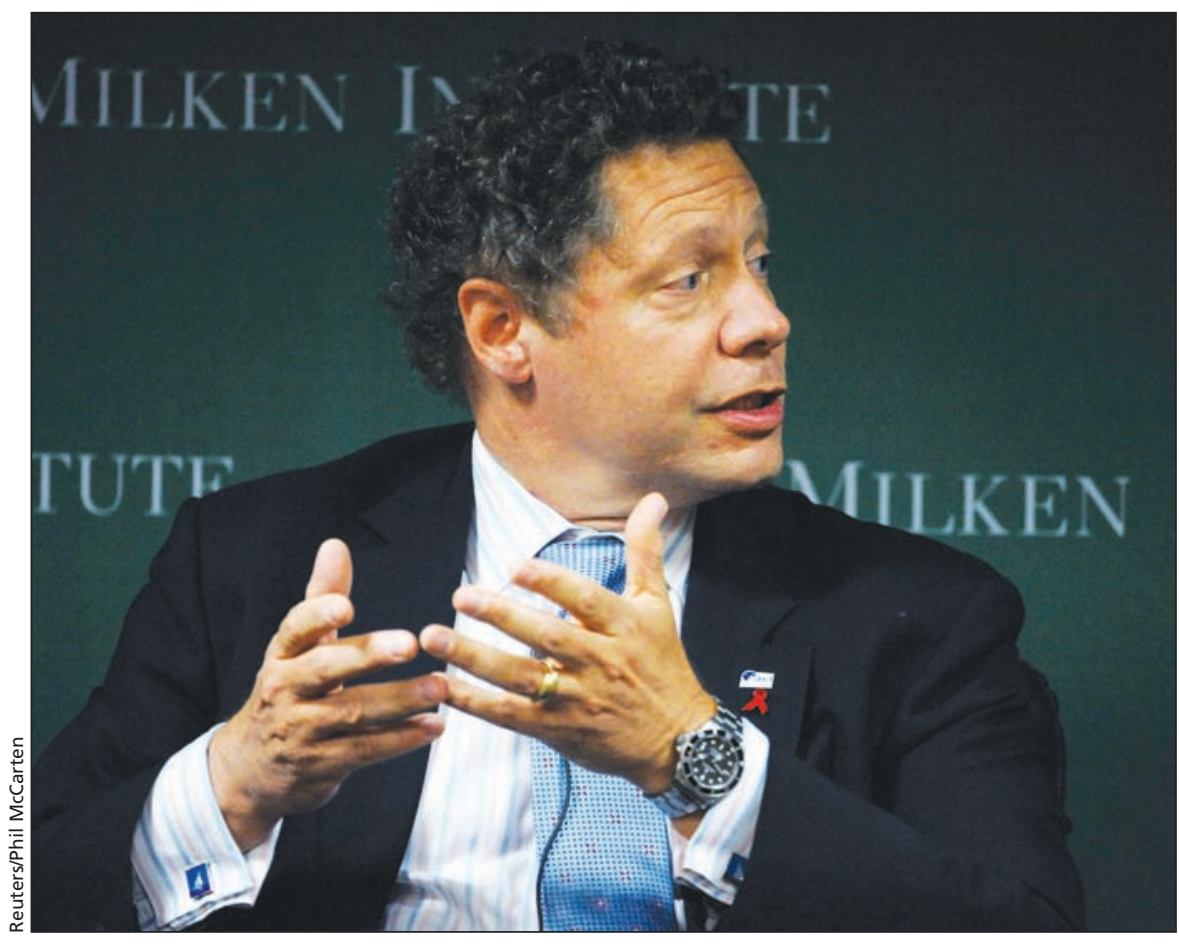

Companies are becoming more engaged in producing treatments for the developing world through product development partnerships, says Seth Berkley, president of the International AIDS Vaccine Initiative.

Diseases Initiative and the Medicines for Malaria Venture.

To that end, a veritable 'who's who' of PDPs lined up at a World Health Summit symposium in Berlin to call on governments to follow the lead of Germany, which announced at the event that it is issuing a \$US20-million PDP request for proposals, with an eye to shifting even more of its global health aid into such vehicles, if they prove themselves in the competition.

The PDP model was developed in the mid-1990s as a means of redressing what was called the "10/90 gap" — the fact that just $10 \%$ of health research outlays were aimed at diseases that constitute $90 \%$ of the global disease burden.

PDPs are typically not-for-profit organizations which seek to develop products for a range of diseases for which industry believes the develop- ment costs or potential returns don't justify the potential investment costs, such as AIDS, malaria, tuberculosis, leishmaniasis, sleeping sickness, hookworm and dengue fever. To some degree or another, they involve a partnership with a pharmaceutical or a biotech company, and often seek to marry business and innovation skills with academic talents, throwing all that brainpower at developing effective treatments that are affordable by developing countries.

As PDPs have demonstrated in their embryonic years, "you can either end up with the best or the worst of all three of those sectors (industry, academia and government)," Hannah Kettler, senior program officer with the Bill \& Melinda Gates Foundation, told the symposium.

Skeptics have questioned whether PDPs can escape conflicts of interest 
given that they often, de facto, subsidize industry to develop a drug or vaccine. Other concerns that have been raised include whether PDPs set excessive and untoward conditions on the distribution or use of a drug or vaccine in a recipient country; whether they unfairly impose long-term agreements to provide products at discounted prices (which some recipient countries say is aimed at preventing a local generic industry from being established); and whether, as they develop products, their industrial partners are becoming more aggressive in using intellectual property law to skirt the original goal of providing "reasonably priced" drugs and vaccines.

But symposium panelists extolled PDPs for essentially transforming the nature of health product development.

First and foremost, they've "leveraged" in-kind contributions and even some monies from industry for infectious and neglected diseases, said Christopher J. Elias, president of the Program for Appropriate Technology in Health. By sharing the costs and risks of product development, a PDP can "incent companies that would otherwise sit on the sidelines."

"Companies are becoming more engaged," added Seth Berkley, presi- dent of the International AIDS Vaccine Initiative.

The research and development equation has changed, said Mel Spigelman, chief executive officer of the Global Alliance for TB Drug Development. "Because of an up-front investment, it no longer has to be a high commercial return in order to develop these products."

Moreover, PDPs have delivered on their promise to produce products, added Shing Chang, director of research and development for the Drugs for Neglected Diseases Initiatives. The PDP has already produced three products (the fixed-dose antimalarials ASAQ and ASMQ, and a nifutimoxeflornithine combination treatment for the advanced stage of sleeping sickness) and has three more in the pipeline for the next six months, he said.

Panelists also argued that PDPs have helped to develop clinical trials capabilities in recipient nations (although critics have countered that trial design in the developing world often doesn't meet the same ethical standard used in industrialized nations).

Several panelists also indicated that PDPs have work to do on developing the capabilities of recipient nations to utilize developed products. As Elias noted, "there's not enough refrigerator capacity (in developing nations) for all the vaccines that are coming."

To that end, several of the PDP officials said they are adopting an "advocacy" role in a bid to ensure that health delivery mechanisms, such as staff and facilities, actually exist to administer a drug or vaccine within a recipient nation once its government has purchased it.

Kettler later indicated in an interview that the Gates foundation considers PDPs a highly successful model of global health investment and the return on investment more than adequate.

"When you look at how much has been spent and how many products, I mean, I think the latest is that something like 93 candidates are in development," she says. "That's vaccines, drugs and diagnostics. And that number changes every day. Instead of reducing that number, just that that's multiple tens of more than were in clinical testing 10 years ago. And even if you do the math and you say (US)\$3 billion, for that many products, that's very good value for money." Wayne Kondro, CMAJ

DOI:10.1503/cmaj.109-3699 